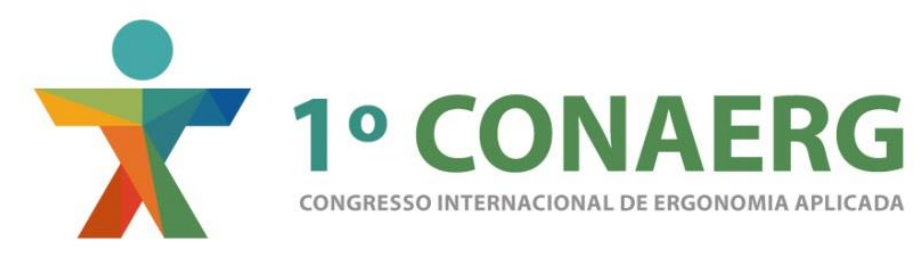

\title{
ANTROPOMETRIA APLICADA AO DESIGN DE PRODUTOS: UM ESTUDO DE CASO DE DIMENSIONAMENTO DE ARMÁRIO DE GUARDAR ROUPA PARA CADEIRANTES
}

\author{
Suzi Maria Mariño (1); \\ Carina Santos Silveira (2); \\ Rita Caroline de Silva (3) \\ (1) Universidade do Estado da Bahia, Universidade Federal da Bahia, Doutora \\ e-mail: suzimarino@gmail.com \\ (2) Universidade Federal da Bahia, Doutoranda em Artes Visuais \\ e-mail: carinassilveira@gmail.com \\ (3) Universidade do Estado da Bahia, Designer \\ e-mail: rcaroline72@@gmail.com
}

\begin{abstract}
RESUMO
Este artigo traz uma discussão sobre a importância da aplicação da antropometria e a seleção do percentil correto para o dimensionamento de produtos e faz um recorte para o dimensionamento de armários de guardar roupas para cadeirantes. Discute como é abordada a acessibilidade no projeto de móveis sob medida e a possibilidade de projeto e execução de armários para guardar roupa acessíveis e universal. Para isso, foi necessária uma investigação e coleta de informações a respeito do caso estudado tornando-o mais compreensível. O objetivo como resultado inicial a ser abordado neste artigo, apontar a utilização da antropometria como referência para o dimensionamento de produtos e, mais especificamente, para o desenvolvimento de móveis acessíveis, tendo como estudo de caso os armários para guarda roupa, baseado nos princípios do Design Universal de modo a garantir a acessibilidade destes.
\end{abstract}

\footnotetext{
ABSTRACT

This article presents a discussion of the importance of the application of anthropometry and the correct selection percentile for the design of products and make a cutout for the design wardrobe cabinets for wheelchair users. Discusses how is addressed accessibility in bespoke furniture design and the ability to design and execution of lockers to store accessible and universal clothing. For this, a research and gathering information about the case study was required making it more understandable. The goal as initial result to be discussed in this article, point the use of anthropometry as a reference for the design of products and, more specifically, to the development of affordable furniture, and as a case study cabinets for wardrobe, based on the principles of Universal Design so as to ensure their accessibility.
} 


\section{INTRODUÇÃO}

As medidas do corpo humano têm despertado interesse desde a existência da humanidade. Em vários períodos da nossa história, pode-se constatar estudiosos que utilizaram as medidas do corpo humano como referência para suas obras, como a antiga Grécia que teve as medidas do ser humano como referência para construção das mais perfeitas obras que a humanidade já teve conhecimento. Leonardo da Vinci, na Renascença, criou seu desenho da figura humana, baseado nos trabalhos do arquiteto e teoricista romano Vitrívius que, por volta do ano 15 d.C., escreveu um tratado sobre seus estudos de proporção humana. Ao matemático belga, Quetlet, são creditadas a criação e a divulgação do termo "antropometria" a partir de seu trabalho intitulado Antropometrie, de 1870. No entanto, que se tenha notícias, a antropometria só passa a ser utilizada como referência para o projeto de produtos a partir do século XIX. Os dados antropométricos definem as medições de tamanho, peso e proporção do corpo humano aplicáveis a um correto dimensionamento de projeto de produtos, equipamentos e postos de trabalho.

Moraes (1983) conta que, no fim do século XIX e início do século XX, em face do interesse por estudos detalhados do ser humano vivente e do esqueleto de fósseis, a antropometria passou a desempenhar um importante papel, destacando-se Martin, em 1917, e Hrdliçka em 1939.

No início do século XX, continua Moraes (1983), a antropometria, um importante método da antropologia física, experimentou extensivo e rápido crescimento da literatura. $O$ termo antropometria deriva do grego antropos, significando "humano", e metrikos, que significa "medida de". Segundo a autora, a estandardização das medidas do crânio foi resultado do Congresso Internacional de Antropólogos, realizado em Mônaco, em 1906, pois, até então, cada investigador usava técnicas de medição e nomenclaturas diferentes. Como consequência disso, as comparações entre os resultados eram difíceis.

As 38 medidas do crânio e 19 da cabeça e face do vivente tornaram-se padrões seguidos por antropólogos de todo o mundo. Uma segunda estandardização das medidas do vivente, excluindo-se a cabeça, aplicavase principalmente ao esqueleto, e foi resultado do 'Congresso Internacional de 1912', em Genebra. Em 1913, Martin publicou a primeira edição de seu famoso "Lehrbuch der Anthropologie", que permaneceu como obra básica por várias décadas e que, de fato, unificou largamente as técnicas de medida. (MORAES, 1983).

Para Boueri (1991), a antropometria é a aplicação dos métodos científicos de medidas físicas nos seres humanos, buscando determinar as diferenças entre indivíduos e grupos sociais, com a finalidade de se obter informações utilizadas nos projetos de arquitetura, urbanismo, design e de engenharia, e, de um modo geral, para melhor adequar esses produtos a seus usuários.

Como se sabe, todas as populações são compostas de indivíduos de diferentes tipos físicos que apresentam diferenças nas proporções de cada segmento do corpo. Com as viagens de Marco Polo (1273-1295), segundo Guimarães (2004), foi revelada a existência de um grande número de raças que diferiam, inclusive, em termos de dimensões do corpo. 
Como citado anteriormente, a preocupação com a antropometria teve impulso a partir da década de 40 do século $X X$, pelas exigências da produção em massa, quando superdimensionamentos de poucos centímetros passaram a significar aumento considerável nos custos de produção de centenas de milhares de um mesmo produto. Não se pode deixar de mencionar que em um projeto aeroespacial cada centímetro ou quilograma pode comprometer o desempenho da nave, e um controle fora do raio de ação de um operador de um sistema complexo pode representar a resposta tardia com resultados catastróficos.

\begin{abstract}
Até a década de 1950, havia uma preocupação em estabelecer padrões nacionais antropométricos. Mas, a partir de então, a economia começou a se internacionalizar com a expansão da produção em massa, culminando na globalização atual da economia. Hoje, é possível atender os padrões de qualquer mercado, já que é possível acessar tabelas de muitas populações que habitam este planeta. Algumas estão tabuladas em mídia eletrônica, outras em papel, mas o que importa é a confiabilidade dos dados de uma determinada população. (GUIMARÃES, 2004).
\end{abstract}

Com o passar dos anos, a necessidade por medidas mais exatas do ser humano foi crescendo. Hoje, estas medidas são imprescindíveis para o dimensionamento de produtos eficientes. Em todo o mundo vem crescendo a Antropometria aplicada ao dimensionamento de produtos.

Segundo Moraes (1983), os objetivos e atitudes dos primeiros pesquisadores eram um tanto diversos daqueles dos antropometristas ligados à Ergonomia. Consequentemente, seus métodos eram diferentes.

No entanto, muitos de seus resultados ainda são úteis ao designer, e seus métodos podem ser adaptados aos problemas presentes. Algumas de suas descobertas são ainda os únicos dados disponíveis; assim, o conhecimento de seus métodos é vital para o entendimento de alguns dados. Muitos trabalhos aplicados usam técnicas que vieram dos antropólogos físicos, mas ocorreram muitas mudanças no enfoque, no tipo de dados coletados, nos instrumentos especiais para medição que surgiram de necessidades práticas. Em particular, a necessidade de estabelecer relações espaciais em coordenadas tri-dimensionais, envolvendo profundidades e alcances, desenvolveu-se como característica da aplicação da Antropometria ligada à Ergonomia. O designer deve conhecer não só o comprimento e a largura das partes do corpo, mas também onde elas se localizam quando da atividade humana. Tal fato determinou, não só a necessidade de outros métodos que não os de medição com os antropômetros tradicionais, como também a proposição de novas variáveis como largura bi-deltóide, largura cotovelo a cotovelo em abdução, profundidade nádega-joelho etc. (MORAES, 1983)

\title{
1.1 A Antropometria aplicada ao design de produtos
}

Moraes (1983) definia os objetivos da antropometria como:

- Obter dados sobre as medidas do corpo que descrevam com confiabilidade as características, capacidades de alcance, superfície de trabalho para uso normal e máximo, ângulos de conforto, distribuição de peso, volume etc., para grupos, raças ou descendência estudada; 
- Publicar os dados de forma que possam ser usados com facilidade e segurança para comparações e deduções ergonômicas;

Para o dimensionamento de produtos ergonômicos faz-se necessária a aplicação correta das dimensões humanas. Hoje a evolução das formas de análise de dados estatísticos aperfeiçoa as informações levantadas em uma pesquisa de dados antropométricos. Moraes (1983) também ressaltava que:

[...] mais importante, ainda, foi a inovação de métodos computadorizados para a manipulação de modelos matemáticos dos processos biomecânicos. Os conceitos e amplitude dos dados disponíveis atualmente colocaram uma grande variedade de modelos matemáticos do ser humano dentro do âmbito da exequibilidade, e pesquisadores já começaram a desenvolver tais modelos. Com estes objetivos identificaram áreas específicas de conhecimento que são fracas e deficientes em dados diretamente úteis ao desenvolvimento de tais modelos conceituais. Há um interesse crescente e uma nova ênfase nas descrições tridimensionais do corpo e na pesquisa de medições de articulações funcionais do corpo. (MORAES, 1983)

A autora lembrava que um bom início é tentar estandardizar a nomenclatura das variáveis antropométricas, denominando e localizando corretamente os pontos a serem medidos.

\subsection{Fatores que influenciam as diferenças antropométricas}

De acordo com Moraes (1983), os fatores que influenciam as diferenças antropométricas podem ser divididos em fatores intrínsecos e extrínsecos. Boueri (1991) define estes dois tipos; observando que os intrínsecos são fatores próprios da pessoa, tais como alinhamento postural e mobilidade das juntas, e dá como exemplo a gravidez, que altera a linha do corpo ou, ainda, o fato de que, do nascimento até os 25 anos de idade, aumentamos de estatura $70 \%$ e, depois, decrescemos até $7,5 \mathrm{~cm}$. Os fatores extrínsecos são conceituados por ele como fatores externos, como clima e vestuário, e cita como exemplo o fato de que a roupa altera as dimensões do corpo e as suas condições dinâmicas.

Quaresma (2001) subdivide os fatores intrínsecos em sexo, idade, etnia e raça, tipo de atividade, nível socioeconômico e a tendência secular ou gerações da população e divide os fatores extrínsecos em vestuário e equipamentos, postura e horário. A autora enfatiza que, para a correta seleção da população usuária, devem ser levados em consideração todos estes fatores.

\subsection{Aplicação dos dados antropométricos ao dimensionamento da zona interfacial}

\subsubsection{Definição de percentis corretos}

De acordo com Soares e Siqueira (2002), percentis são usados para entender bem uma distribuição. Para isso, é necessário que se conheçam valores acima ou abaixo dos quais se encontra uma determinada porcentagem dos dados.

Boueri (1991) define percentil como uma medida de dispersão das dimensões do corpo humano para a distribuição estatística, sendo a única maneira de determinar o padrão dimensional, sem incorrer em erro de conceitos matemáticos nas aferições de medidas.

A utilização de percentis é uma forma de dividir uma distribuição normal desde o valor 
mínimo até o máximo, segundo uma sequência ordenada. Os percentis extremos, sejam máximos ou mínimos, apresentam pequena probabilidade de incidência.

Guimarães (2004) explica mais detalhadamente o conceito de percentil da seguinte forma: o $\mathrm{x}^{0}$ percentil significa que $\mathrm{x} \%$ das pessoas do levantamento antropométrico considerado tem medidas inferiores ou iguais às deste percentil, e que $100-x \%$ das pessoas tem medidas superiores às deste percentil. Por exemplo, o valor do 95을 percentil para estatura demonstra que $95 \%$ da população têm uma medida de estatura menor ou igual ao do 95ำ percentil e que $5 \%$ possuem estatura com valor maior. Uma medida do 50 percentil mostra que $5 \%$ da população possui esta medida com valor menor ou igual a deste percentil e que $95 \%$ possuem esta medida com valor maior. $050^{\circ}$ percentil corresponde à média.

Moraes (1983) esclarece que, devido às significantes variações nos tamanhos do corpo de cada indivíduo, as 'médias' são de pouca utilidade. Portanto é necessário trabalhar com limites de variação. Estatisticamente, pode-se constatar que as medidas do corpo humano, de qualquer população dada, distribuem-se de tal modo que, de alguma maneira, cairão em algum lugar pelo meio da curva de distribuição, enquanto um pequeno número de medidas extremas cairá em uma das extremidades do espectro. Por isso, a maioria dos dados antropométricos é, em geral, apresentada sob a forma de percentis. A população é dividida, objetivando seu estudo, em 100 percentis, a partir do menor para o maior, em relação a algum tipo específico de dimensão corporal.

Embora o limite máximo de faixa de usuários de um produto compreenda todo o espectro, ou seja, $100 \%$ da população, para esta faixa o projeto é, em geral, técnica e economicamente inviável.

A autora conclui que, num projeto, objetiva-se, em princípio, sua adaptação às características dimensionais de, no mínimo, 90\% dos usuários, ou seja, as pessoas cujas dimensões variam entre os $5^{\circ}$ e $95^{\circ}$ percentis. Omitem-se, portanto, os dois extremos da população, excetuando-se naturalmente, os casos dos equipamentos, que devem considerar necessariamente os indivíduos extremos; como, por exemplo, uma saída de emergência. Existem, também, produtos que são fabricados com dimensões diversas, de modo que cada combinação de dimensões atenda a uma faixa da população, como os números de calçados, os manequins de peças do vestuário etc. (MORAES, 1983).

\subsubsection{A utilização das variáveis antropométricas do 'homem médio'}

Verificou-se a existência de várias referências para a utilização de dados antropométricos para o desenvolvimento de projetos de produtos e arquitetônicos a partir da utilização das variáveis antropométricas do homem médio. Este fato se dá pela dificuldade que se tem para que um produto se adapte às várias dimensões de usuários e, achando esta a melhor forma de uma adaptação ao maior número de usuários, alguns profissionais recorrem a esta forma. Esta prática tem sido constante e isto tem causado grande transtorno, pois o fato de utilizar a média como referência tem resultado em produtos inadequados dimensionalmente, os quais, na maioria das vezes, não atendem a nem metade da população à qual se destina o produto.

Moraes (1983, p.267) esclarece que projetar para uma pessoa média pode conduzir a perigosos erros - $50 \%$ de qualquer grupo sofrerá prejuízos ao utilizar um produto dimensionado para $050^{\circ}$ percentil. Por exemplo, os menores que $50^{\circ}$ percentil não 
alcançarão um controle adequado ao operador médio ou do $50^{\circ}$ percentil. Por outro lado, se uma cadeira for feita para acomodar os quadris da mulher do $50^{\circ}$ percentil, a outra metade que tem quadris maiores estará desacomodada.

Panero (2003) também exemplifica tal fato através de um gráfico onde aparecem os perfis das dimensões de três indivíduos. Percebe-se que se esses indivíduos tivessem todas as dimensões corporais nos mesmos percentis as linhas da Figura 1 apareceriam retas, no entanto, o que ocorre é justamente o contrário, as linhas têm forma totalmente irregular, pois os indivíduos têm valores de percentil diferentes para cada uma das dimensões corporais.

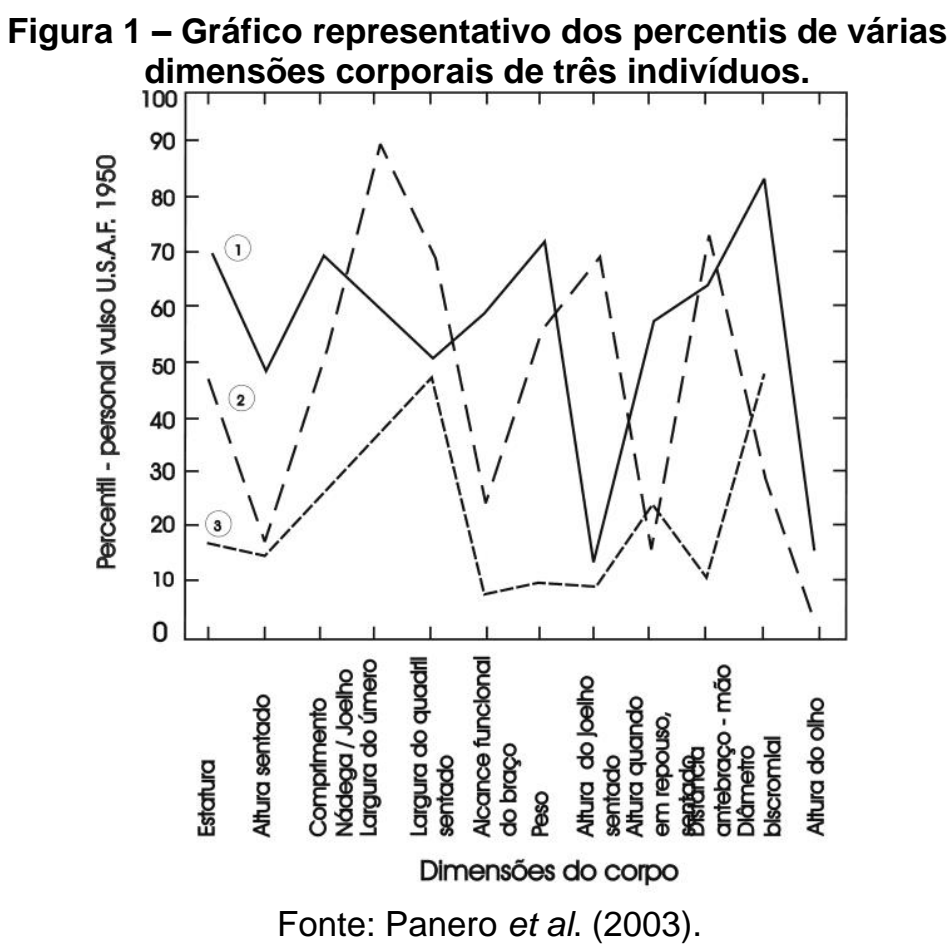

Portanto, como já foi visto, utilizar dados antropométricos considerando a existência de um indivíduo de percentil constante ou do tal 'homem médio' é estar sujeito a cometer erros graves, pois tais indivíduos só existem a partir de uma abstração estatística. O indivíduo de um determinado percentil não existe na realidade e corresponde a uma coleção dos valores do percentil.

Moraes (1983, p.272) lembra que a utilização de manequins antropométricos de 5 e 95은 percentis é mais útil e correto do que o uso de uma única representação do $50^{\circ}$ percentil, ou seja, do 'homem médio'. Ao utilizar os dois extremos $5^{\circ}$ e $95^{\circ}$ percentis os quais indicam limites máximos e mínimos de variação, pode-se prevenir muitos erros grosseiros no projeto de estações de trabalho, equipamentos e produtos.

A seleção dos dados antropométricos adequados baseia-se na natureza do problema particular em questão. Se o projeto requer, por exemplo, que o usuário alcance algo, esteja ele sentado ou de pé, o 5ำ percentil é o indicado. Tal dado, relativo ao alcance de braço, demostra que $95 \%$ da população deve ter um alcance de braço maior. Se o projeto permite acomodar o usuário com menor alcance de braço, obviamente funcionará igualmente para aqueles com alcances maiores (MORAES, 1983, p.267).

Em algumas situações, o ideal é proporcionar, dentro das possibilidades, elementos 
ajustáveis. O limite de variação do ajuste deve tomar como base as características antropométricas do usuário, a natureza da tarefa e as limitações físicas e mecânicas envolvidas. Porém a utilização de ajustes também requer muito critério, pois pode levar a inviabilizar o projeto economicamente e do ponto de vista de produção. Abordaremos esta questão mais adiante, em um item específico.

\section{DESIGN UNIVERSAL}

A utilização de um método para o desenvolvimento de um móvel é de extrema importância. Os resultados obtidos pelos meios empregados para obter dados e conclusões acerca do problema do espaço residencial e o móvel que irá se inserido, como também os novos modos de vida contemporânea e as características e rotina das pessoas que irão usufruir daquele espaço. O conceito de Design Universal está relacionado ao conceito de sociedade inclusiva focado em produto, serviços e ambientes para serem usados pelo maior número de pessoas independente de idade, habilidade ou situação sócio econômica.

Ron Mace Arquiteto e Designer norte-americano cunhou o conceito de Design Universal em 1970. Mace era cadeirante, por conta da Poliomielite, doença que teve na infância. Para ele o projeto de início deve considerar as diversidades de necessidades humanas, uma concepção que atenda diferentes deficiências sem que seja necessário uma adaptação ou um projeto exclusivo para esse tipo de público. Com a finalidade que projetos conciliem as diversas e complexas necessidades em um só projeto, o Design Universal projeta espaços, equipamentos, objetos e ações que reconheçam que as pessoas são naturalmente diferentes.

O Design Universal é definido em sete princípios, sendo uma teoria de projeto e uma fonte de avaliação seja ele gráfico, produto, arquitetônico ou organizacional.

Uma equipe do the center for universal design (Centro para o Design Universal da Universidade Estadual da Carolina do Norte - EUA), como parte do seu projeto "Estudos para Incrementar o Desenvolvimento do Design Universal" Dirigiu uma sucessão de avaliações para determinar as características de funcionamento e elementos de produtos de consumo, espaços arquitetônicos e elementos de construção, para que sejam usados na maior extensão de pessoas possíveis, sem a obrigação de adaptação ou desenho especializado. The center for universal design, formou um grupo de arquitetos, designers de produto, engenheiros e pesquisadores de concepção ambiental, determinando sete princípios do Desenho Universal. Estes princípios são para um melhor direcionamento das disciplinas de design para que sejam aplicadas na analise de projetos existentes, processos criativos e instruir designers e consumidores sobre as propriedades dos produtos e ambientes mais aproveitáveis.

\subsection{Os princípios do Desenho Universal são apresentados, na seguinte forma:}

2.1.1 Uso Equitativo (com igualdade): produtos e ambientes devem ser planejados para serem utilizados por pessoas com diferentes habilidades e características, assim evitando marginalizar qualquer tipo de usuário;

2.1.2 Flexibilidade no Uso: produtos e ambientes devem ser flexíveis, onde há a possibilidade do usuário escolher a forma de utilização, favorecendo as habilidades pessoais e preferências e ritmo; 
2.1.3 Uso Simples e Intuitivo: O design deve ser compreensível, independentemente da experiência do usuário, o entendimento, os conhecimentos linguísticos, ou nível de absorção atual;

2.1.4 Informação Perceptível: O design direciona de forma eficiente a informação necessária para o usuário, independentemente das suas condições ambientais ou habilidade de percepção;

2.1.5 Tolerância ao Erro: $O$ design reduz o risco de acidentes e as consequências adversas de ações. São advertências ou métodos de prevenção para acidentes, para diminuir o risco de acidentes involuntários ou imprevistos;

2.1.6 Baixo Esforço Físico: O design deve ser usado de forma eficiente e satisfatória e com um mínimo de fadiga. Dispor de formas eficientes para evitar fadiga no usuário tornando aquela atividade exercida confortável;

2.1.7 Tamanho e Espaço para Aproximação e Uso: O Designer deve estabelecer dimensões para que o ambiente e espaço, sejam apropriados 0 acesso, alcance, manipulação e uso, independentemente do tamanho do corpo do usuário, postura ou mobilidade. Proporcionar uma visão clara e livre dos elementos dos elementos importantes, independentemente da posição do usuário. Que todo o tipo de usuário, (criança, idoso, pessoas com deficiência física, etc.) possa alcançar e acomodar de forma confortável, todos os tipos de constituintes a seu redor.

\section{LEVANTAMENTO DE DADOS ANTROPOMÉTRICOS PARA O DIMENSIONAMENTO DE ARMÁRIOS DE GUARDAR ROUPA PARA CADEIRANTES}

\subsection{Seleção de variáveis antropométricas}

Além da seleção dos percentis corretos para o desenvolvimento de um projeto de produto, faz-se necessário a correta seleção das variáveis antropométricas. Na verdade, uma das maiores razões de erro na aplicação de dados antropométricos encontra-se na seleção incorreta da variável pertinente.

É frequente a utilização da estatura para definir o local de melhor visualização de mostradores, quando o certo seria utilizar a altura do nível dos olhos e, a partir daí, delimitar o campo de visão. Outro erro cometido é a seleção da largura de ombros bideltóide, quando o que se quer é dimensionar a largura do apoio lombar. Neste caso, seria melhor, então, a largura do tórax entre as axilas, para não atrapalhar a movimentação do usuário. Tal fato explica parcialmente por que, até em países onde existe profusão de levantamentos, os produtos não são bem dimensionados (MORAES, 1994, p.37).

Moraes (1983, p.327) lembra que se deve observar a especificidade do projeto, explicitada a partir da análise da tarefa, pois só dessa forma é que se determinará, em última instância, as variáveis que serão necessárias ao dimensionamento da estação de trabalho ou produto.

\subsection{Variáveis antropométricas para dimensionamento de armários para guardar roupa}

As recomendações para o dimensionamento de armário de guardar roupas para cadeirantes que aqui apresentamos estão baseadas no referencial teórico levantado, assim como no nas 
referências de Panero (2003) cujas indicações mostraram que o correto dimensionamento de um produto fundamentais para o conforto dos usuários e a prevenção de patologias.

Ressaltamos que as recomendações aqui elaboradas apenas servem como referência para um primeiro passo ao se dimensionar um armário de guardar roupas. Estes dados são teóricos e devem ser exaustivamente testados quanto à validade através da elaboração de testes antes da elaboração do produto final quando feito sob medida para um único usuário ou encaminhamento dos projetos para linha de produção.

Foram levantadas as variáveis antropométricas para dimensionamento considerando os $5^{\circ} \mathrm{e}$ 95ำ percentis, sendo o $5^{\circ}$ da mulher e 95 do homem de forma a atender a $90 \%$ da população usuária.

Quadro 1 - Variáveis antropométricas para dimensionamento de armários para guardar roupa

\begin{tabular}{|c|c|c|c|c|c|}
\hline $\begin{array}{c}\text { Variáveis } \\
\text { dimensionais }\end{array}$ & $\begin{array}{c}\text { Variáveis } \\
\text { antropométricas }\end{array}$ & $\begin{array}{c}\text { Percentil } \\
\text { Mulher } 5 \\
\text { Homem } 95\end{array}$ & $\begin{array}{l}\text { Dimensões } \\
(\mathrm{cm})\end{array}$ & Figuras & \\
\hline $\begin{array}{l}\text { Profundidade } \\
\text { do armário }\end{array}$ & $\begin{array}{l}\text { Comprimento } \\
\text { da articulação do } \\
\text { ombro até a } \\
\text { extremidade do } \\
\text { dedo médio na } \\
\text { postura sentada }\end{array}$ & Mulher 5 & 66,0 máx. & & \\
\hline $\begin{array}{l}\text { Altura } \\
\text { máxima da } \\
\text { arara }\end{array}$ & $\begin{array}{l}\text { Alcance superior } \\
\text { até a } \\
\text { extremidade do } \\
\text { dedo médio na } \\
\text { postura sentada }\end{array}$ & Mulher 5 & 137,2 máx. & & \\
\hline $\begin{array}{l}\text { Altura } \\
\text { mínima da } \\
\text { arara }\end{array}$ & $\begin{array}{l}\text { Alcance médio } \\
\text { do braço } \\
\text { estendido na } \\
\text { horizontal na } \\
\text { postura sentada }\end{array}$ & Mulher 5 & 86,4 máx & & \\
\hline
\end{tabular}




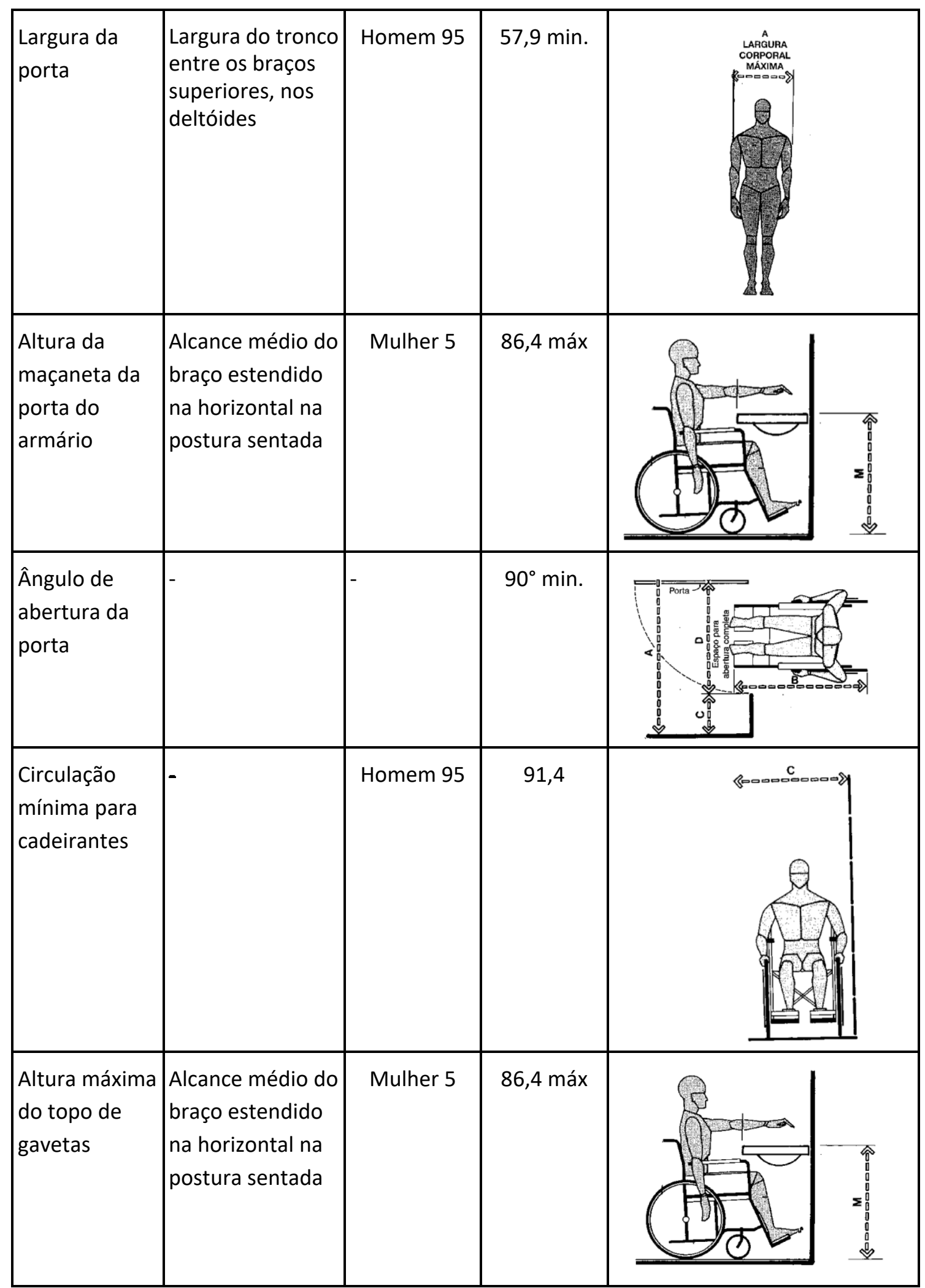




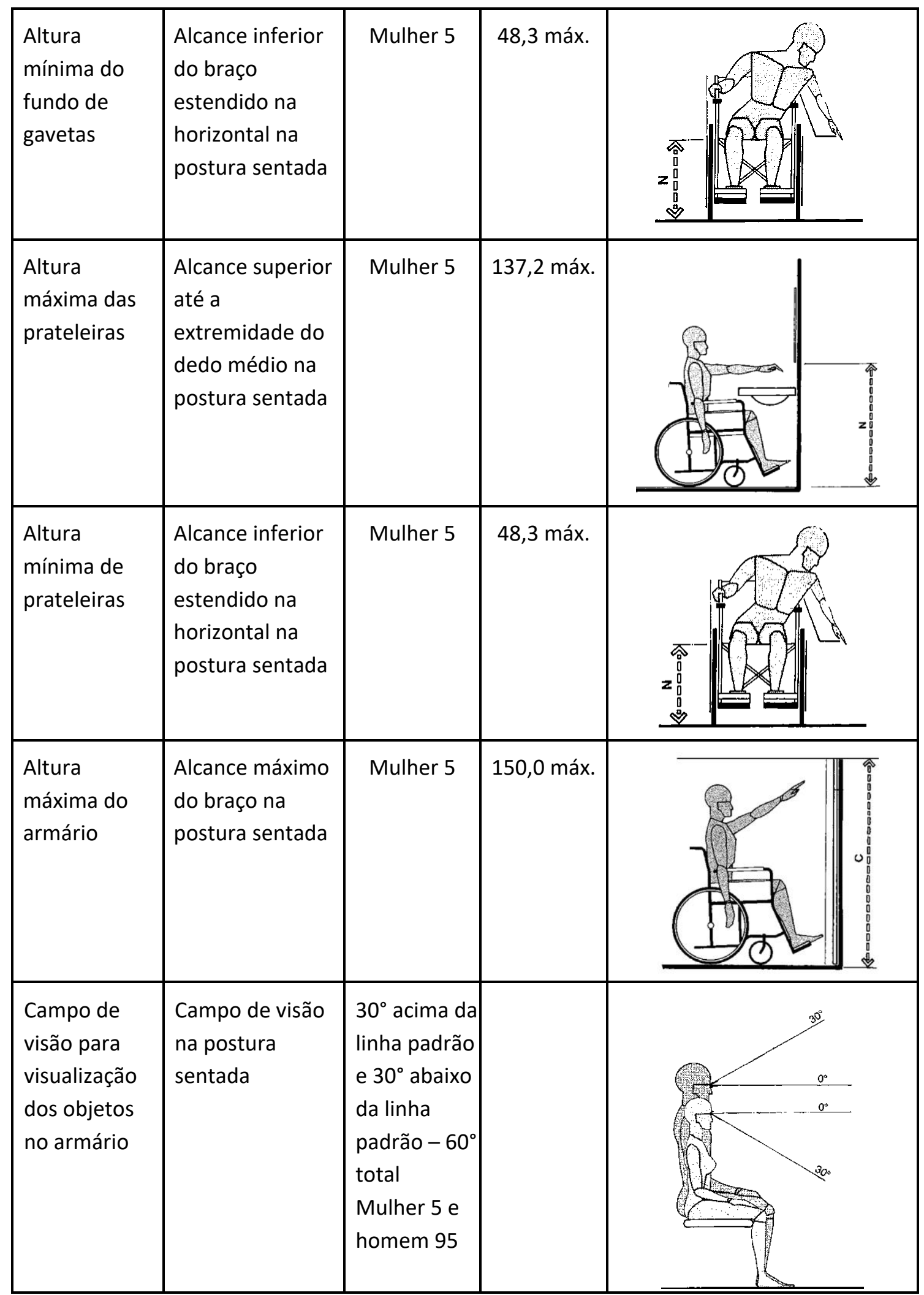

Fonte: elaborado pelos autores, com base na pesquisa realizada. Imagens de Panero (2003).

\section{CONCLUSÃO}

Com base na análise feita até o momento, as pessoas com deficiência adquiriram grandes conquistas a partir da década de 90 , tanto no campo de pesquisa como em leis que garante o direito de acessibilidade, identificando e eliminando as diversas barreiras que impeçam a 
realização e exerçam as atividades no corpo social, a fim de garantir uma sociedade democrática. Portanto a antropometria e a ergonomia, sob o vetor do design, trazem estudos de medidas físicas do corpo humano e sua relação com o trabalho originando resultados que garantam as modificações nos diversos âmbitos sociais dando autonomia nos espaços, mobiliários e equipamentos urbanos, nas edificações, serviços de transporte e dispositivos, sistemas e meios de comunicação e informação.

Considera-se para tanto, de modo conclusivo e pautado nos limiares da pesquisa, que a aplicação adequada das práticas projetuais, associadas aos princípios do Design Universal e o emprego de requisitos antropométricos, permitirão o desenvolvimento de mobiliário acessível e adaptado à inclusão de todas ou da maioria das pessoas ao uso do mesmo. No estudo aqui proposto, os requisitos antropométricos delimitados deverão, exclusivamente ser aplicados ao projeto de guarda roupas. No entanto, cabe ao designer, partindo do mesmo princípio aqui exposto, estabelecer parâmetros projetuais adequados ao uso no que tange a relação homem $X$ tarefa $X$ máquina.

A pesquisa encontra-se em fase de validação, onde os dados conclusivos serão aplicados ao desenvolvimento de um protótipo para avaliar e consolidar a pertinência dos dados apresentados.

Sugere-se como propostas futuras a continuidade da pesquisa no âmbito de estudo de requisitos para outros mobiliários, propor um ambiente mobiliado inclusivo; bem como o estudo de aplicação dos parâmetros citados à indústria moveleira. Aqui também se propõe o uso do resultado da pesquisa, bem como da sua continuidade, pautada na produção industrial com valor acessível à maioria.

\section{REFERÊNCIAS BIBLIOGRÁFICAS}

ABNT NBR 9050. Acessibilidade a edificações, mobiliário, espaços e equipamentos urbanos. Rio de Janeiro, 2004.

BOUERI, José Jorge. Antropometria aplicada à Arquitetura, Urbanismo e Desenho Industrial. São Paulo, FAU/USP, 1991, v. 1.

FRANCISCO, Paulo e MENEZES Alexandre. Design Universal, acessibilidade e espaço construído. Belo Horizonte, 2011.

DEVIDES Maria T.C. Design, Projeto e Produto: 0 desenvolvimento de móveis nas indústrias do Pólo Moveleiro de Arapongas, PR. Bauru, SP, 2006.

DISCHINER Marta, ELY Vera, PIARDI Sonia. Promovendo acessibilidade espacial nos edifícios públicos: Programa de Acessibilidade às Pessoas com Deficiência ou Mobilidade Reduzida nas Edificações de Uso Público. Florianópolis, 2012. (Ministério Público Do Estado De Santa Catarina Procuradoria Geral De Justiça - Centro de Apoio Operacional dos Direitos Humanos e Terceiro Setor).

GUIMARÃES, Lia Buarque Macedo de. Ergonomia do produto: Antropometria, Fisiologia, Biomecânica. Porto Alegre: Feeng, 2004. 1 v. (2).

Instituto Brasileiro de Geografia e Estatística. Dados sobre Pessoa com deficiência no Brasil. 2010. Disponível em: <http://teen.ibge.gov.br/calendario-teen-7a12/evento/1096-dia-internacionaldas-pessoas-com-deficiencia.html>. Acesso em: 06 de Abril de 2016.

MORAIS, Anamaria de (A). Aplicação de dados antropométricos dimensionamento da interface homem-maquina. Dissertação de mestrado. Rio de Janeiro:

COPPE/UFRJ,1983. 
MORAES, Anamaria de (B). Conformação da interface homem-máquina: usuários extremos versus homem brasileiro. In: MORAES, A.; VELLOSO, F. (org) Anais do $2^{\circ}$ Encontro carioca de ergonomia. Rio de Janeiro: ABERGO, 1994, p. 33 - 45.

PANERO, Juliua MARTIN, Zelnik. Dimensionamento Humano para Espaços Interiores: Um Livro De Consulta e Referência Para Projetos. Editora: GGbrasil.

Ano: 2003.

QUARESMA, Maria Manuela Rupp. Aplicação de dados antropométricos em projeto de design: como projetar corretamente produtos ergonômicos. Dissertação (Mestrado em Design). PUC/Rio, Rio de Janeiro, 2001.

SOARES, J. F.; SIQUEIRA, A. L. Introdução à estatística médica. Belo Horizonte: Departamento de Estatística - UFMG, 1999. 